\begin{tabular}{|c|c|c|c|c|c|}
\hline $\begin{array}{c}\text { Laboraiory } \\
\text { number }\end{array}$ & $\begin{array}{l}\text { Published } \\
\text { reference }\end{array}$ & $\begin{array}{l}\text { Original date or } \\
\text { other value }\end{array}$ & $\begin{array}{l}\text { Corrected date } \\
\text { or other value }\end{array}$ & $\partial \mathrm{C}^{14}, \%$ & $\begin{array}{c}\text { A.D./ } \\
\text { B.C. date }\end{array}$ \\
\hline-30 & $68: 110$ & $2626 \pm 105$ & & & 676 B.C. \\
\hline-34 & $69: 102$ & $4794 \pm 90$ & & & 2844 B.C. \\
\hline-35 & $68: 110$ & $8940 \pm 273$ & & & 6990 B.C. \\
\hline-33 & $68: 107$ & $5326 \pm 180$ & & & 3376 B.C. \\
\hline-45 & $69: 100$ & $6247 \pm 130$ & & & 4297 B.C. \\
\hline-47 & $69: 101$ & $9465 \mathrm{~d}$ & & & \\
\hline-49 & $69: 100$ & $4770 \pm 110$ & & & 2820 B.C. \\
\hline .50 & $69: 101$ & $4306 \pm 105$ & & & 2356 B.C. \\
\hline-53 & $69: 103$ & $3240 \pm 110$ & & & 1290 B.C. \\
\hline-54 & $69: 103$ & $3030 \pm 75$ & & & 1080 B.C. \\
\hline-7.5 & $69: 104$ & $10,090 \pm 215$ & & & 8140 B.C. \\
\hline-80 & $69: 102$ & $3366 \pm 130$ & & & 14.16 B.C. \\
\hline$-8 \mathrm{l}$ & $69: 102$ & $3099 \pm 120$ & & & 1149 B.C. \\
\hline-84 & $69: 103$ & $744 \pm 100$ & & & A.D. 1206 \\
\hline-87 & $69: 102$ & $3341 \pm 115$ & & & 1391 B.C. \\
\hline-83 & $69: 102$ & $3137 \pm 105$ & & & 1187 B.C. \\
\hline$-9 \mathrm{I}$ & $69: 102$ & $2944 \pm 105$ & & & 994 B.C. \\
\hline-94 & $69: 103$ & $2780 \pm 95$ & & & 830 B.C. \\
\hline-100 & $69: 102$ & $4248 \pm 115$ & & & 2298 B.C. \\
\hline-101 & $69: 100$ & $6578 \pm 135$ & & & 4228 B.C. \\
\hline-115 & $69: 104$ & $5646 \pm 220$ & & & 3696 B.C. \\
\hline$-119^{2}$ & $69: 99$ & $9694 \pm 110$ & & & 7744 B.C. \\
\hline$-151^{2}$ & $69: 104$ & $2991 \pm 115$ & & & 1041 B.C. \\
\hline-152 & $69: 100$ & $14,488 \pm 800$ & & & 12,538 B.C. \\
\hline$-153^{2}$ & $69: 100$ & $10,581 \pm 100$ & & & 8631 B.C. \\
\hline
\end{tabular}

${ }^{1}$ Reference standard was modern wood and shows Suess effect; unless otherwise noted, measurements have not been corrected.

${ }^{2}$ Reference standard was pre-industrial wood.

\title{
Packard Instrument Company, Inc.
}

\begin{tabular}{|c|c|c|c|c|c|}
\hline $\begin{array}{l}\text { Laboratory } \\
\text { number }\end{array}$ & $\begin{array}{l}\text { Published } \\
\text { reference }\end{array}$ & $\begin{array}{l}\text { Original date or } \\
\text { other value }\end{array}$ & $\begin{array}{l}\text { Corrected date } \\
\text { or other value }\end{array}$ & $\partial \mathrm{C}^{14}, \%$ & $\begin{array}{l}\text { A.D. } \\
\text { B.C. date }\end{array}$ \\
\hline PIC-... ${ }^{1}$ & $165: 202$ & $12,000 \pm 300$ & & & 10,050 B.C. \\
\hline$-2^{2}$ & $165: 202$ & $11,000 \pm 350$ & & & 9050 B.C. \\
\hline$-3^{3}$ & $165: 202$ & $8900 \pm 200$ & & & 6950 B.C. \\
\hline-4 & $165: 202$ & $10,340 \pm 475$ & & & 8390 B.C. \\
\hline $.5^{4}$ & $165: 203$ & $8080 \pm 165$ & & & 6130 B.C. \\
\hline$-6^{5}$ & $165: 203$ & $10,450 \pm 150$ & & & 8500 B.C. \\
\hline .7 & $165: 203$ & $6230 \pm 430$ & & & 4280 B.C. \\
\hline-8 & $165: 203$ & $4750 \pm 200$ & & & 2800 B.C. \\
\hline-9 & $165: 203$ & $5850 \pm 320$ & & & 3900 B.C. \\
\hline -10) & $165: 204$ & $6500 \pm 200$ & & & 4550 B.C. \\
\hline
\end{tabular}

${ }^{1}$ Cross-checks: C-800; L-698D, Tx-44.

${ }^{2}$ Cross-check: Tx-160

${ }^{3}$ Cross-check: Tx-159.

${ }^{4}$ Cross-check: Tx-157.

${ }^{5}$ Cross-check: Tx-158.

\section{Cambridge, University Sub-Department of Quaternary Research ${ }^{\mathbf{1}}$}

\begin{tabular}{|c|c|c|c|c|c|}
\hline $\begin{array}{l}\text { Laboratory } \\
\text { number }\end{array}$ & $\begin{array}{l}\text { Published } \\
\text { reference }\end{array}$ & $\begin{array}{l}\text { Original date or } \\
\quad \text { other value }\end{array}$ & $\begin{array}{l}\text { Corrected date } \\
\text { or other value }\end{array}$ & $\partial \mathrm{C}^{14}, \%$ & $\begin{array}{c}\text { A.D./ } \\
\text { B.C. date }\end{array}$ \\
\hline Q-]. & $44: 73$ & $7770 \pm 100$ & & & 5820 B.C. \\
\hline-2 & $44: 67$ & $11,071 \pm 180$ & & & 9121 B.C. \\
\hline-3 & $44: 73$ & $8190 \pm 180$ & i & & 6240 B.C. \\
\hline$-\ddot{z}$ & $44: 71$ & $2520 \pm 110$ & & & 570 B.C. \\
\hline-9 & $46: 74$ & $3880 \pm 90$ & & & 1930 B.C. \\
\hline-14 & $44: 69$ & $9557 \pm 210$ & & & 7607 B.C. \\
\hline
\end{tabular}

